\title{
A multivariate analysis of risk factors associated with death by Covid-19 in the USA, Italy, Spain, and Germany
}

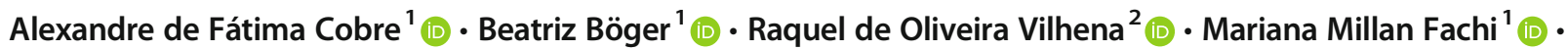 \\ Josiane Marlei Muller Fernandes dos Santos ${ }^{1}$ (D) Fernanda Stumpf Tonin ${ }^{1}$ (D)
}

Received: 13 July 2020 / Accepted: 5 October 2020 / Published online: 19 October 2020

(C) Springer-Verlag GmbH Germany, part of Springer Nature 2020

\begin{abstract}
Aim Our aim was to investigate the risk factors associated with death from COVID-19 in four countries: The USA, Italy, Spain, and Germany.

Subject and methods We used data from the Institute for Health Metrics and Evaluation with projection information from JanuaryAugust 2020. A multivariate analysis of logistic regression was performed. The following factors were analyzed (per day): number of beds needed for the hospital services, number of intensive care units (ICU) beds required, number of ventilation devices, number of both hospital and ICU admissions due to COVID-19. Nagelkerke's $\mathrm{R}^{2}$ coefficient of determination was used to evaluate the model's predictive ability. The quality of the model's fit was assessed by the Hosmer-Lemeshow and the chi-square tests.

Results Among the evaluated countries, Italy presented greater need for ICU beds/day $(\leq 98$; OR $=2315.122$; CI 95\% [334.767$16,503.502] ; p<0.001)$ and daily ventilation devices $(\leq 118 ; \mathrm{OR}=1784.168 ; \mathrm{CI} 95 \%[250.217-12,721.995] ; p<0.001)$. It is expected that both Italy and Spain have a higher ICU admission rate due to COVID-19 $(n=14 /$ day). Spain will need more beds/day $(\leq 357$; OR $=146.838 ;$ CI 95\% [113.242-190.402]; $p<0.001)$ and probably will have a higher number of daily hospital admissions $(n=48 /$ day). All the above-mentioned factors have an important impact on patients' mortality due to COVID-19 in all four countries.

Conclusions Further investments in hospitals' infrastructure, as well as the development of innovative devices for patient's ventilation, are paramount to fight the pandemic in the USA, Italy, Spain, and Germany.
\end{abstract}

Keywords COVID-19 $\cdot$ Risk factors $\cdot$ USA $\cdot$ Italy $\cdot$ Spain $\cdot$ Germany

\section{Introduction}

The present study was carried out on April 19, 2020, then all the data used in this study refer to the period from the beginning of the COVID-19 pandemic to the month of April of this year. The World Health Organization recorded more than 4 million confirmed cases and 224 thousand deaths by the new Coronavirus disease 2019 (COVID-19) in more than 208

Beatriz Böger

beatrizboger@gmail.com

Alexandre de Fátima Cobre alexandrecobre@gmail.com

Raquel de Oliveira Vilhena raquel.vilhena@hotmail.com

Mariana Millan Fachi

marianamfachi@gmail.com countries. The largest number of confirmed cases was reported by the United States of America (USA) $(n=1,060,572)$, Spain $(n=212,917)$, Italy $(n=203,597)$, France $(n=$ $128,442)$, and Germany $(n=161,187)$ (Arabi et al. 2020; WHO 2020a). The exponential increase in the number of infected individuals, especially critically ill patients, is challenging public health systems worldwide. The infections caused by the SARS-COV-2 virus can be asymptomatic or cause mild

Josiane Marlei Muller Fernandes dos Santos josianemullerfernandes@gmail.com

Fernanda Stumpf Tonin

ffstonin@gmail.com

1 Pharmaceutical Sciences Postgraduate Program, Federal University of Paraná, Curitiba, Brazil

2 Department of Pharmacy, Pharmaceutical Sciences Postgraduate Program, Federal University of Paraná, Av. Lothário Meissner, 632, Paraná, Curitiba 80210-170, Brazil 
symptoms in the respiratory tract (e.g., dry cough, fever). However, severe cases of the disease are characterized by difficulty breathing and chest pain, usually requiring treatment in intensive care units (ICU) (Chen et al. 2020; Huang et al. 2020; RKI 2020; Rodriguez-Morales et al. 2020a; Rodriguez-Morales et al. 2020b). Severe cases often occur in patients over 50 years old, in whom mortality rates are higher (Cascella et al. 2020; Chen et al. 2020; Huang et al. 2020; Lai et al. 2020). Unfortunately, mortality rates are not always accurately assessed, as not all asymptomatic patients or those with mild symptoms are completely recorded by the healthcare systems. The calculation is usually based on incomplete follow-up data (i.e., underestimation due to delayed deaths). Therefore, data comparisons between countries may be difficult due to differences in the populations originally affected by the virus. For instance, the elderly were primarily the most infected group in Italy, which was not the scenario in Germany (Saglietto et al. 2020; Weiss and Murdoch 2020).

Currently, COVID-19 mortality rates have ranged from $0.3 \%$ to $5.8 \%$, being significantly higher compared to the seasonal influenza (0.1\%) (Anderson et al. 2020; Li et al. 2017; WHO 2020a; WHO 2020b; WHO 2020c). The reduction of these rates depends, among other things, on the capacity and quality of services of the healthcare system of each country (Müller et al. 2020). In many countries, the amount of mechanical ventilation and ICU beds available for the treatment of critically ill patients is far from ideal. So far, no specific antiviral treatment or vaccine for COVID-19 exist (Chen et al. 2020; Huang et al. 2020). The most favorable coping strategy to deal with this infection has been prevention, aiming at reducing community transmission of the virus. In the past days, aggressive measures of social distance (isolation) in China led to a progressive reduction in the number of cases (Cascella et al. 2020).

Our aim was to investigate the predictors of COVID-19 mortality in some of the most affected countries (i.e., USA, Italy, Spain, and Germany) including clinical and quality-ofservice indicators such as number of beds and ventilation devices available, number of hospitalizations, and number of patients attending ICU.

\section{Methods}

\section{Study design and data collection}

An epidemiological study was conducted using the Coronavirus Projections Database from the Institute for Health Metrics and Evaluation (IHME) of the University of Washington (USA) (IHME 2020).

Data were projected from January 3 to August 4, 2020. Only information from the USA, Italy, Spain, and Germany was evaluated. Data from other European countries have been excluded. The number of required beds/day, number of required ICU beds/day, number of ventilation devices, number of new hospital admissions/day, and number of new ICU patients/day were considered as independent variables for patients affected by COVID-19. The dependent variable was death by COVID-19, which was dichotomized into death or life.

\section{Statistical analyses}

Quantitative data with normal distribution were presented as a mean and 95\% confidence interval (CI). The categorical (qualitative) variables were presented as frequency. The evaluation of risk factors associated with mortality due to COVID19 was conducted using the multivariate model of logistic regression. The quantification of the effect size of the mortality risk factors was performed using the odds ratio (OR) with a $95 \%$ CI. The model was built using hierarchical criteria based on theoretical reasons. Nagelkerke's $\mathrm{R}^{2}$ coefficient of determination was used to evaluate the model's predictive ability. The quality of the model's fit was assessed by the HosmerLemeshow and chi-square tests. Statistical analyses were performed using SPSS Software version 20 (Chicago, USA). A level of significance of $p<0.05$ was considered statistically significant.

\section{Results}

In the USA, the estimated number of beds in hospitals was 174 beds/day (CI 95\%, 1.04-3.85), while in Italy, Spain, and Germany the numbers were 347 beds/day (CI 95\%, 3.074.22), 357 beds/day (CI 95\%, 2.96-4.93), and 96 beds/day (CI 95\%, 6.9-1.85) respectively. Regarding the number of beds required in ICU for treating COVID-19, the values were 48 beds/day in the USA, while Italy and Spain presented similar rates (98 and 97 beds/day respectively), and Germany had the lowest values ( 26 beds/day). Italy and Spain also showed the highest numbers of ventilation equipments ( 88 and 87 devices/beds/day respectively), followed by USA (43 devices/beds/day) and Germany (24 devices/beds/day). These same patterns were observed for hospital admissions due to COVID-19 (Italy: 47 beds/day, Spain: 48 beds/day, USA: 24 beds/day, Germany: 13 beds/day) and ICU admissions (Italy: 14 beds/day, Spain: 14 beds/day, USA: 7 beds/day, Germany: 4 beds/day) (Table 1). During the studied period, the cumulative forecast of deaths from COVID-19 in the USA was 620 (CI 95\%, 4.08-12.53), while in Italy it was 1428 deaths (CI 95\%, 13.17-16.60), in Spain 1359 (CI 95\%, 11.80-17.82) and in Germany 352 deaths (CI 95\%, 2.69-6.44).

All the above-mentioned factors (number of daily hospital beds, ICU beds, ventilation devices, hospital, and ICU 
Table 1 Forecast of average number of beds, ventilation devices and hospital admissions per day for treating COVID-19 in the USA, Italy, Spain, and Germany (03/01/2020-04/08/2020)

\begin{tabular}{|c|c|c|c|c|c|c|c|c|c|c|c|c|}
\hline \multirow[t]{2}{*}{ Variable } & \multicolumn{3}{|l|}{ USA } & \multicolumn{3}{|l|}{ Italy } & \multicolumn{3}{|l|}{ Spain } & \multicolumn{3}{|c|}{ Germany } \\
\hline & Mean & $-95 \% \mathrm{CI}$ & $+95 \% \mathrm{CI}$ & Mean & $-95 \% \mathrm{CI}$ & $+95 \% \mathrm{CI}$ & Mean & $-95 \% \mathrm{CI}$ & $+95 \% \mathrm{CI}$ & Mean & $-95 \% \mathrm{CI}$ & $+95 \% \mathrm{CI}$ \\
\hline Number of beds/day & 174 & 104 & 385 & 347 & 307 & 422 & 357 & 296 & 493 & 96 & 69 & 185 \\
\hline Number of ICU beds/day & 48 & 29 & 104 & 98 & 88 & 118 & 97 & 82 & 133 & 26 & 19 & 51 \\
\hline $\begin{array}{l}\text { Number of ventilation } \\
\text { devices/bed/day }\end{array}$ & 43 & 26 & 92 & 88 & 79 & 106 & 87 & 73 & 119 & 24 & 17 & 45 \\
\hline $\begin{array}{l}\text { Number of hospital } \\
\text { admissions/day }\end{array}$ & 24 & 13 & 53 & 47 & 40 & 60 & 48 & 38 & 69 & 13 & 9 & 26 \\
\hline $\begin{array}{l}\text { Number of ICU } \\
\text { admissions/day }\end{array}$ & 7 & 4 & 14 & 14 & 12 & 17 & 14 & 11 & 19 & 4 & 3 & 7 \\
\hline $\begin{array}{l}\text { Cumulative deaths } \\
\text { (COVID-19) }\end{array}$ & 620 & 408 & 1253 & 1428 & 1317 & 1660 & 1359 & 1180 & 1782 & 352 & 269 & 644 \\
\hline
\end{tabular}

$\mathrm{CI}=$ confidence interval

admission) were associated with the risk of death by COVID19 in the four countries (chi-square test of model adjustment, $p<0.05)$. The prediction of the regression models was greater than $97 \%\left(\mathrm{R}^{2}\right.$ Negelkerk $\left.>0.85\right)$ and the observed data were statistically like the predicted data (Hosmer-Lemeshow, $p>0.05$ ) (Table 2).

The risk factors associated with COVID-19 mortality in the USA were: having a number of hospital beds equal or less than 174 per day $[\mathrm{OR}=286.344$ (CI 95\% 208.962392.381); $p<0.001]$ having a number of ICU beds for COVID-19 lower than 48 per day $[\mathrm{OR}=284.585$ (CI 95\% 206.916-391.408); $p<0.001$ ]; having less than 43 available ventillation devices per day $[\mathrm{OR}=349.251$ (CI 95\% 243.715500,488); $p<0.001]$; number of hospital admissions equal or superior to 24 patients per day $[\mathrm{OR}=120.738$ (CI 95\% 95.670-152.375); $p<0.001]$ and number of patients attending ICU due to COVID-19 higher than 7 per day [OR $=146.838$ (CI 95\% 113.242-190.402); $p<0.001]$ (Table 3). In Italy, the risk factors associated with COVID-19 mortality were: having a number of hospital beds equal or less than $347(p<0.001)$; having a number of ICU beds for COVID-19 lower than 98 $(p<0.001)$; having less than 118 available ventilation devices per day $(p<0.001)$; number of hospital admissions equal or superior to 47 patients per day $(p<0.001)$; and number of patients attending ICU higher than 14 per day $(p<0.001)$ (Table 3).
In Spain, the risk factors associated with mortality from COVID-19 were: the number of hospital beds less than 357 available per day $[\mathrm{OR}=146.838$ (CI 95\% 113.242-190.402); $p<0.001]$; number of ICU beds less than 98 per day $[\mathrm{OR}=$ 195.673 (CI 95\% 62.340-614.183); $p<0.001$ ]; number of ventilation devices less than 87 per day $[\mathrm{OR}=676.618$ (CI 95\% 215.921-2120.278); $p<0.001]$; number of hospital admissions equal or greater than 48 patients/day [OR $=284.449$ (CI 95\% 133.435-606.370); $p<0.001]$; and number of ICU admission superior to 14 patients daily [OR $=277.808$ (CI 95\% 130.314 592.239); $p<0.001]$ (Table 3). The risk factors associated with COVID-19 mortality in Germany were: number of hospital beds less than 96 per day $(p<0.001)$; number of ICU beds less than 26 per day $(p<0.001)$; number of ventilation devices less than 24 per day $(p<0.001)$; number of hospital admissions greater 13 daily $(p<0.001)$ and number ICU admissions superior to 4 patients per day $(p<0.001)$ (Table 3$)$.

\section{Discussion}

Our study demonstrated with a 7-month projection (January 2020 until August 2020) the low number of both beds in ICU and ventilation devices available per day being associated with an increase of 100-fold (OR > 100) in mortality from COVID19 in all four evaluated countries (USA, Spain, Italy, and

Table 2 Chi-square test for coefficient significance analysis, Nalgelkerk R2 and Hosmer-Lemeshow tests for adjustment analysis of the multivariate logistic regression model of all studied variables

\begin{tabular}{llll}
\hline Model & Chi-square test " $p$ value" & Hosmer-Lemeshow test " $p$ value" & Nagelkerk R $^{2}$ \\
\hline USA & 0.000 & 0.080 & 0.88 \\
Italy & 0.000 & 0.784 & 0.87 \\
Spain & 0.000 & 0.435 & 0.88 \\
Germany & 0.000 & 0.052 & 0.86 \\
\hline
\end{tabular}




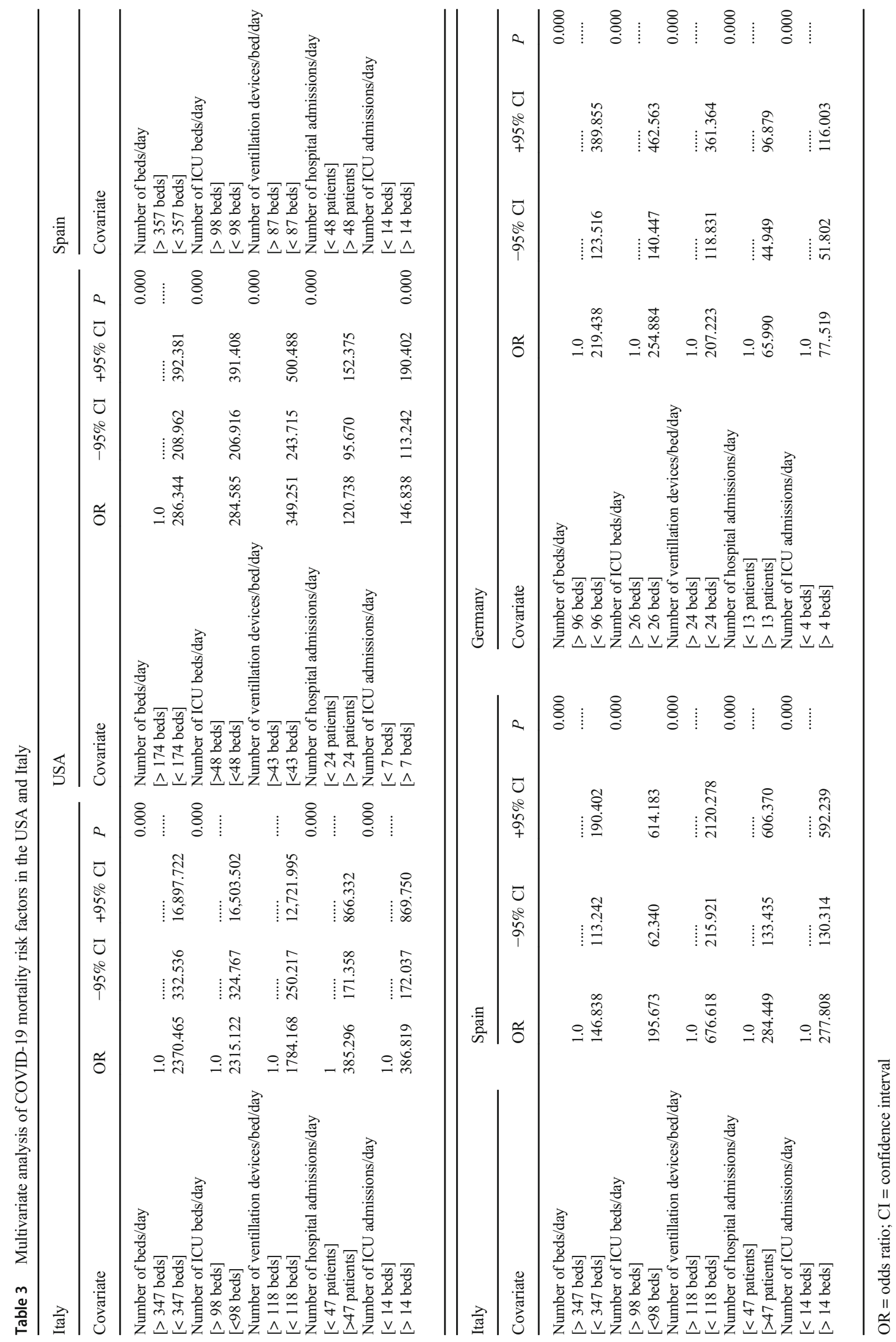


Germany) if no further measures were taken. These four countries were chosen because they had the highest numbers of predicted cases and the highest mortality from COVID-19 in the database used. In China (Wuhan), where the pandemic started, $49 \%$ of all 2087 inpatients seriously affected by COVID-19 died, reaching a mortality rate around $62 \%$. In the USA, these rates are already around 52\% (Washington, DC) (Phua et al. 2020). Given that the mortality of severely ill patients with SARS-CoV-2 pneumonia is high, and that the survival time of these patients ranges from 1 to 2 weeks in hospital beds, the lack of infrastructure for treating patients with COVID-19 will impact on the disease's course. Additionally, hospitals must provide areas and beds with minimum safety parameters to admit routine patients that are not infected with the virus, but still need care, avoiding extending morbimortality to other diseases (Remuzzi and Remuzzi 2020).

The reduced number of hospital beds predisposes the healthcare system to saturation (Di Lorenzo and Di Trolio 2020). The need for measures such as increasing the number of ICU beds had already been foreseen in some studies carried out for European countries, such as the study of Verelst et al. (2020). In Italy, one of the countries most affected by the pandemic worldwide, it is estimated that the number of ICU beds needed to provide a minimum set of care for COVID-19 patients will reach several thousand. According to the study by Verelst et al. (2020) which was carried out with data available until the beginning of March 2020 in Italy, maximum occupancy of all available beds in the country was predicted ( $n=5200$ ) by the end of the same month, pointing out the need for allocation of resources to increase the number of beds in order to contribute to coping with the pandemic (Verelst et al. 2020). In the study of Remuzzi and Remuzzi (2020), a projection of the number of patients in ICU beds was calculated from February 2020, reaching up to 7500 ICU beds in a week in Italy if the infection rate continued to increase (Remuzzi and Remuzzi 2020).

A study published by Rhodes et al. (2012) evidenced a very considerable heterogeneity in the number of ICU beds among European countries, with Germany, for instance, having 6.9 times the number of beds per capita compared to other nations (Rhodes et al. 2012). These differences may be explained, among others, by socioeconomic variances among regions and by features of the healthcare systems (Rhodes et al. 2012). This heterogeneity among the countries was also evident regarding the need for structure during a COVID-19 pandemic. While Italy and Spain identified the number of ICU beds of 98 per day as a risk factor associated with COVID-19 mortality, Germany showing the number of 26 per day. In an intermediate position to European countries, the USA showed the number of 48 ICU beds per day as a risk factor. The same ranking was observed when comparing the other risk factors, as the total number of hospital beds and the number of available ventillation devices per day. The worst results were pointed out for Italy and Spain, followed by the USA, while Germany presented the best scenario.

Patients infected with COVID-19 that require hospitalization are usually classified according to the clinical manifestations and disease severity into: (1) mild disease with pneumonia or absence ( $81 \%$ of cases), (2) severe disease with dyspnea, altered respiratory rate, blood oxygen saturation $\leq 93 \%$, change in the $\mathrm{PaO} 2 / \mathrm{FiO} 2$ or $\mathrm{P} / \mathrm{F}$ ratio and the percentage of oxygen supplied with possible pulmonary infiltrate (14\% of cases), and (3) critical illness with respiratory failure, septic shock, or multiple organ dysfunction (MOD) or failure (MOF) (5\% of cases) (Cascella et al. 2020). In a retrospective cohort study of 201 patients with confirmed COVID-19 pneumonia admitted to Wuhan Jinyintan Hospital in China between December 25, 2019, and January 26, 2020, 82.1\% of patients $(n=165)$ required oxygen support in the hospital (Wu et al. 2020; Wu and McGoogan 2020). In mainland China, it was estimated that $3.2 \%$ of all patients infected with COVID-19 received intubation and invasive ventilation (Meng et al. 2020). Despite the small percentage of patients requiring invasive ventilation, the large number of infected patients simultaneously may mean limited access to this type of treatment resource (Whittle et al. 2020). There is an estimate that in the USA there are about 60,000 to 160,000 , depending on the functionality of the equipment (Ranney et al. 2020). However, according to the present study, less than 43 ventilator devices available per day was a risk factor for death, that is, the number of ventilators in the country is critical in view of the growing increase in COVID-19 cases. The scenario is even more critical when we look at the figures for Italy and Spain (118 per day and 87 per day respectively), which are countries that already lack these fans (Rosenbaum 2020).

Although the pandemic requires a significant increase in the number of beds in hospitals, the circumstances can also reduce the available resources. The SARS outbreak in Toronto led to the closure during 10 days of $38 \%$ of the ICU beds at a tertiary care university, mainly due to the lack of professionals, who have been affected by the disease or were in quarantine. In this context, in addition to increasing the capacity of beds and availability of ventilators, hospitals must have strategies to increase the safety of the employees (Arabi et al. 2020).

Our results confirm the statement of the World Health Organization that COVID-19 is an emergency public health problem of worldwide interest, both for developed countries (such as the USA, Spain, Italy, and Germany) and for developing countries. This disease saturates local health systems, regardless of the country. In this context, it is important to reinforce further preventive public measures, such as quarantine, for the control of the disease. Quarantined people contribute to the reduction of new viral infections, consequently reducing overcrowding of hospitals. Additionally, further investments in hospitals' 
infrastructure are needed, as well the development of innovative devices for patient's ventilation.

The present study is based on prediction data, which may represent a limitation. The predictions on the number of new cases and mortality may not reflect the complete reality in all countries, but rather give an overall idea of what may happen until August. Besides that, it was not possible to assess the association of different variables related to healthcare access (e.g., healthcare settings, categories of care) on COVID-19 outcomes, as these data were not available on the consulted database. Further studies considering this information are needed to better understand the impact of different healthcare services on disease evolution.

\section{Conclusions}

The number of ICU beds, ventilation devices, hospital admissions, and ICU admissions per day due to COVID-19 are important predictors of mortality in the USA, Italy, Spain, and Germany. In these countries, there is an urgent need to expand hospitals' infrastructure and services and increase the production of devices used to treat patients with this disease. Political leaders and healthcare officials should ensure that minimum resources are safely provided, including staff, hospital beds, and ICU.

Acknowledgments The authors express their gratitude for research funding to the CAPES (Brazilian Federal Agency for Support and Evaluation of Graduate Education within the Ministry of Education of Brazil) - Finance Code 001

Contribution author(s) Study concepts: AFC, BB, FST.

Study design: AFC, BB, ROV, MMF.

Data analysis and interpretation: AFC, ROV, MMF.

Statistical analysis: AFC, FST, BB, JMMFS.

Manuscript preparation and editing: AFC, FST, BB, ROV, MMF, JMMFS.

Manuscript review: FST, ROV.

\section{Compliance with ethical standards}

Conflict of interest The authors declare that they have no conflict of interest.

\section{References}

Anderson RM, Heesterbeek H, Klinkenberg D, Hollingsworth TD (2020) How will country-based mitigation measures influence the course of the COVID-19 epidemic? Lancet 395:931-934. https://doi.org/10. 1016/s0140-6736(20)30567-5

Arabi YM, Murthy S, Webb S (2020) COVID-19: a novel coronavirus and a novel challenge for critical care. Intensive Care Med 46:833836. https://doi.org/10.1007/s00134-020-05955-1
Cascella M, Rajnik M, Cuomo A, Dulebohn SC, Di Napoli R (2020) Features, evaluation, and treatment of Coronavirus (COVID-19). In: StatPearls. StatPearls Publishing, Treasure Island, FL

Chen $\mathrm{N}$ et al (2020) Epidemiological and clinical characteristics of 99 cases of 2019 novel coronavirus pneumonia in Wuhan, China: a descriptive study. Lancet 395:507-513. https://doi.org/10.1016/ s0140-6736(20)30211-7

Di Lorenzo G, Di Trolio R (2020) Coronavirus disease (COVID-19) in Italy: analysis of risk factors and proposed remedial measures. Front Med 7:140. https://doi.org/10.3389/fmed.2020.00140

Huang C et al (2020) Clinical features of patients infected with 2019 novel coronavirus in Wuhan, China. Lancet 395:497-506. https:// doi.org/10.1016/s0140-6736(20)30183-5

IHME (2020) 17. IHME - Institute for Health Metrics and Evaluation. COVID-19 projections. https://covid19.healthdata.org/unitedstates-of-america. Accessed 26.04.2020 2020

Lai CC, Wang CY, Wang YH, Hsueh SC, Ko WC, Hsueh PR (2020) Global epidemiology of coronavirus disease 2019 (COVID-19): disease incidence, daily cumulative index, mortality, and their association with country healthcare resources and economic status. Int J Antimicrob Agents 55:105946. https://doi.org/10.1016/j. ijantimicag.2020.105946

Li L, Wong JY, Wu P, Bond HS, Lau EHY, Sullivan SG, Cowling BJ (2017) Heterogeneity in estimates of the impact of influenza on population mortality: a systematic review. Am J Epidemiol 187: 378-388. https://doi.org/10.1093/aje/kwx270

Meng L et al (2020) Intubation and ventilation amid the COVID-19 outbreak: Wuhan's experience. Anesthesiology 132:1317-1332. https://doi.org/10.1097/aln.0000000000003296

Müller O, Neuhann F, Razum O (2020) Epidemiology and control of COVID-19. Dtsch Med Wochenschr 145:670-674 [Article in German]. https://doi.org/10.1055/a-1162-1987

Phua J et al (2020) Intensive care management of coronavirus disease 2019 (COVID-19): challenges and recommendations. Lancet Respir Med 8:506-517. https://doi.org/10.1016/S2213-2600(20)30161-2

Ranney ML, Griffeth V, Jha AK (2020) Critical supply shortages - the need for ventilators and personal protective equipment during the Covid-19 pandemic. N Engl J Med 382:e41. https://doi.org/10. 1056/NEJMp2006141

Remuzzi A, Remuzzi G (2020) COVID-19 and Italy: what next? Lancet 395:1225-1228. https://doi.org/10.1016/S0140-6736(20)30627-9

Rhodes A, Ferdinande P, Flaatten H, Guidet B, Metnitz PG, Moreno RP (2012) The variability of critical care bed numbers in Europe. Intensive Care Med 38:1647-1653. https://doi.org/10.1007/ s00134-012-2627-8

RKI (2020) Robert Koch-Institut. Epidemiologisches Bulletin. https:/ www.rki.de/DE/Content/Infekt/EpidBull/Archiv/2020/Ausgaben/ 15_20.pdf?_blob=publicationFile. Accessed 14.04.2020 2020

Rodriguez-Morales AJ et al (2020a) COVID-19 in Latin America: the implications of the first confirmed case in Brazil. Travel Med Infect Dis 35:101613. https://doi.org/10.1016/j.tmaid.2020.101613

Rodriguez-Morales AJ et al. (2020b) Preparation and control of the coronavirus disease 2019 (COVID-19) in Latin America. Acta Peruana Medica 37:3-7 doi:https://doi.org/10.35663/amp.2020. 371.909

Rosenbaum L (2020) Harnessing our humanity — how Washington's health care workers have risen to the pandemic challenge. N Engl J Med 382:2069-2071. https://doi.org/10.1056/NEJMp2007466

Saglietto A, D'Ascenzo F, Zoccai GB, De Ferrari GM (2020) COVID-19 in Europe: the Italian lesson. Lancet 395:1110-1111. https://doi.org/ 10.1016/s0140-6736(20)30690-5

Verelst F, Kuylen E, Beutels P (2020) Indications for healthcare surge capacity in European countries facing an exponential increase in coronavirus disease (COVID-19) cases, March 2020. Eurosurveillance 25:2000323 https://doi.org/10.2807/1560-7917. ES.2020.25.13.2000323 
Weiss P, Murdoch DR (2020) Clinical course and mortality risk of severe COVID-19. Lancet 395:1014-1015. https://doi.org/10.1016/s01406736(20)30633-4

Whittle JS, Pavlov I, Sacchetti AD, Atwood C, Rosenberg MS (2020) Respiratory support for adult patients with COVID-19. J Am Coll Emerg Physicians Open 1(2):95-101. https://doi.org/10.1002/emp2. 12071

WHO (2020a) Intensive care management of coronavirus disease 2019 (COVID-19): challenges and recommendations. WHO, Geneva. https://www.physiciansweekly.com/intensive-care-management-ofcoronavirus-disease-2019-covid-19-challenges-andrecommendations/; . Accessed 26.04.2020 2020

WHO (2020b) Report of the WHO-China Joint Mission on Coronavirus Disease 2019 (COVID-19). WHO, Geneva. https://www.who.int/ publications/i/item/report-of-the-who-china-joint-mission-oncoronavirus-disease-2019-(covid-19). Accessed 26.04.2020 2020
WHO (2020c) Situation in numbers total (new cases in last 24 hours). WHO, Geneva. https://www.who.int/docs/default-source/ coronaviruse/situation-reports/20200426-sitrep-97-covid-19.pdf? sfvrsn=d1c3e800 6;. Accessed 26.04.2020 2020

$\mathrm{Wu} \mathrm{C}$ et al (2020) Risk factors associated with acute respiratory distress syndrome and death in patients with coronavirus disease 2019 pneumonia in Wuhan, China. JAMA Intern Med 180(7):934-943. https://doi.org/10.1001/jamainternmed.2020.0994

Wu Z, McGoogan JM (2020) Characteristics of and important lessons from the coronavirus disease 2019 (COVID-19) outbreak in China: summary of a report of 72,314 cases from the Chinese Center for Disease Control and Prevention. JAMA 323(13):1239-1242. https://doi.org/10.1001/jama.2020.2648

Publisher's note Springer Nature remains neutral with regard to jurisdictional claims in published maps and institutional affiliations. 